\title{
Private outpatient consultations in the NHS- where do we stand?
}

This article is based on a commentary prepared by the BMA secretariat.

\section{Rental agreements}

In October 1977 the Health Services Board reported that it intended to withdraw certain authorisations for the use of NHS accommodation and services by private patients (Cmnd 6963). These included the use of consulting rooms at particular hospitals where it had been "established beyond doubt" (though not always correctly) that the facilities had not been used in 1975 or 1976. In some cases consultants had used accommodation under rental agreements not covered by Section $66^{*}$ of the 1977 NHS Act. But in November 1977 the DHSS decided that health authorities should be advised not to make any new arrangements for leasing, renting, or licensing hospital accommodation to consultants for private consultations, or to renew existing arrangements.

The Joint Consultants Committee maintained that this decision could mean health authorities refusing to renew a rental agreement for a consulting room or similar accommodation earlier than would have been recommended by the board on the basis of usage, demand, and/or availability of alternative facilities. The DHSS accepted this and agreed that a rental agreement should not be ended without consultation with the Health Services Board, taking account of the principles of Section $70 \dagger$ of the 1977 Act. Even so, the Department still intended to advise authorities not to make new agreements or to extend any existing ones to newly appointed consultants if Section 66 facilities co-existed at the hospital. The JCC rejected this proposal since it meant that a newly appointed consultant could have access to pay-beds but would be denied the consulting room facilities that were a normal adjunct to them. The JCC's arguments persuaded the Department to modify its stand and health authorities will now be advised not to enter into new agreements or to extend existing agreements to new doctors where the hospital is authorised under Section 66 of the NHS Act to provide-that is, not rent-consulting room facilities. Where a hospital is not authorised to provide facilities under Section 66, the authority should not renew, extend to new doctors, end, or allow a rental agreement to lapse unless the Secretary of State after consultation with the Health Services Board agrees. These assurances, resulting from JCC pressure are valuable to the profession.

Section 66 applies not just to consulting room facilities but also to other facilities for day cases, such as pathology, radiology, radio-

*Under Section 66 of the NHS Act 1977 the Health Services Board has a duty to propose the progressive revocation of authorisations that permit consultants to use NHS accommodation and services for their non-resident private patients.

†Under Section 70 of the NHS Act 1977 the continued authorisation of pay-beds and other services depends on all reasonable steps having been taken "to provide, otherwise than at NHS hospitals, sufficient reasonable accommodation and facilities for private practice to meet the reasonable demand in the area served by the hospital.' therapy, physiotherapy, operating theatre facilities, and other specialised services. If a rental agreement lapses or is ended there is no guarantee that a Section 66 authorisation will outlive the rental agreement for any particular length of time.

A consultative letter in June 1978 (24 June, p 1712) reported the Health Services Board's intention to make proposals for the revocation of Section 66 authorisations for accommodation and services for diagnostic purposes. These proposals will operate from 1 January 1979. The criteria are that there is either no reasonable demand for such facilities or sufficient alternative facilities elsewhere to cope with any demand. The board is again looking at authorisations where according to its information facilities seem not to have been and the board that it has little faith in the latter's information gathering methods. The information requested is too limited and can lead to errors-for example, the omission of returns about private patients who returned for investigation only in special departments.

Once the Secretary of State has directed

\section{Diagnostic facilities} used. The JCC has regularly told the DHSS

that effect be given to a proposal made by the board that decision cannot be reversed. More disturbing is recent evidence before the JCC that some consultants who wish to do private practice are unaware-even after making inquiries-that authorisations exist for the use of particular diagnostic or other facilities in the hospital for private outpatients; actual demand is therefore hidden.

\section{Private sector alternatives}

While the board is considering pruning Section 66 authorisations for diagnostic facilities, it is also looking at authorised accommodation available for consultation facilities for non-resident private patients. In a letter on 31 July the board said that it proposed to revoke authorisations if it was satisfied that "reasonable steps" had not been taken to provide private sector alternatives (12 August, p 516). Before making any proposals the board has to give "due warning to persons likely to be affected." The board has asked consultants to submit information by 31 January 1979 , with the intention that any proposals should take effect by 1 January 1980 . So it is possible that consultants in certain hospitals might, in 1980 , find themselves without any facility in

\section{BMA work-place representatives}

A recent spate of employment legislation and the introduction of industrial-style closed contracts for junior hospital doctors have made the BMA concentrate more on its role as a trade union. At the ARM in July the Representative Body approved a set of proposals to extend BMA representation into the work place. As a result the BMA is about to appoint its first accredited place-of-work representatives (POWARs).

The Secretary, Dr Elston Grey-Turner, has written to all divisions asking them to identify hospitals where POWARs are needed and, with the help of chairmen of medical staff committees, junior mess presidents, and linkmen, to nominate people willing to serve as POWARs. Preferably, two representatives should be appointed at each hospital-one to represent the training grades and one to represent the career grades. They must be BMA members and work at the hospital concerned. General practitioners may be appointed if they work more than five sessions a week at the hospital.

The Secretary wants the names of the selected doctors to be sent to BMA headquarters for accreditation by the beginning of November. These are only interim arrangements to get POWARs appointed quickly while a formal selection procedure is being set up. Initially only hospitals will be covered, though the POWAR network may be extended to other fields of practice later.

The POWAR will be the BMA's man on the spot. He will recruit new members, provide members with information, and help them with their contract and other problems. In this he will be supported by regional officers, provincial medical secretaries, a new network of regional industrial relations officers, and headquarters staff. Under a code of practice issued by the Advisory, Conciliation, and Arbitration Service (ACAS), which is soon to be incorporated into a General Whitley Council agreement, trade union representatives may take paid time off during working hours to perform their duties. Representatives may also have access to telephone and office facilities, and POWARs who consider that they need such facilities are to make arrangements direct with their employing authorities.

The arrangements to appoint POWARs are separate from those for appointing safety representatives and representatives to joint staff consultative committees. Safety representatives under the Health and Safety at Work Act are being appointed through regional committees for hospital medical services. BMA members on staff consultative committees will continue to be appointed by divisions; they do not have to be POWARs and do not need accreditation, though clearly they will need to liaise with POWARs. 


\section{Pay-beds : proposed withdrawals for 1979}

The Health Services Board has written individually to 17 health authorities with proposals for phasing out further pay-beds from NHS hospitals in 1979. As foreshadowed in the-board's 1977 annual report (1 April, p 870) and its policy paper issued in August (19 August, $p$ 580), the new provisional proposals are based on the board's identification of spare capacity at named private-sector nursing homes and hospitals which might be used to meet all or part of the demand for private medicine at present met by the pay-beds under consideration.

The board is anxious that all consultants engaged in private practice at the affected hospitals should be given an opportunity to make comments, which are requested by 8 January 1979. If the authority cannot accept the reduction proposed the board would like to know the reasons. If it is maintained that the private clinic would be unable to meet any particular part of the demand for private medicine the board wishes to know which diagnoses and or treatment are in question. The authorities should state how many paybeds should be retained at the named authorised hospitals and their reasons.

Consultative proposals for the revocation of pay-bed authorisations

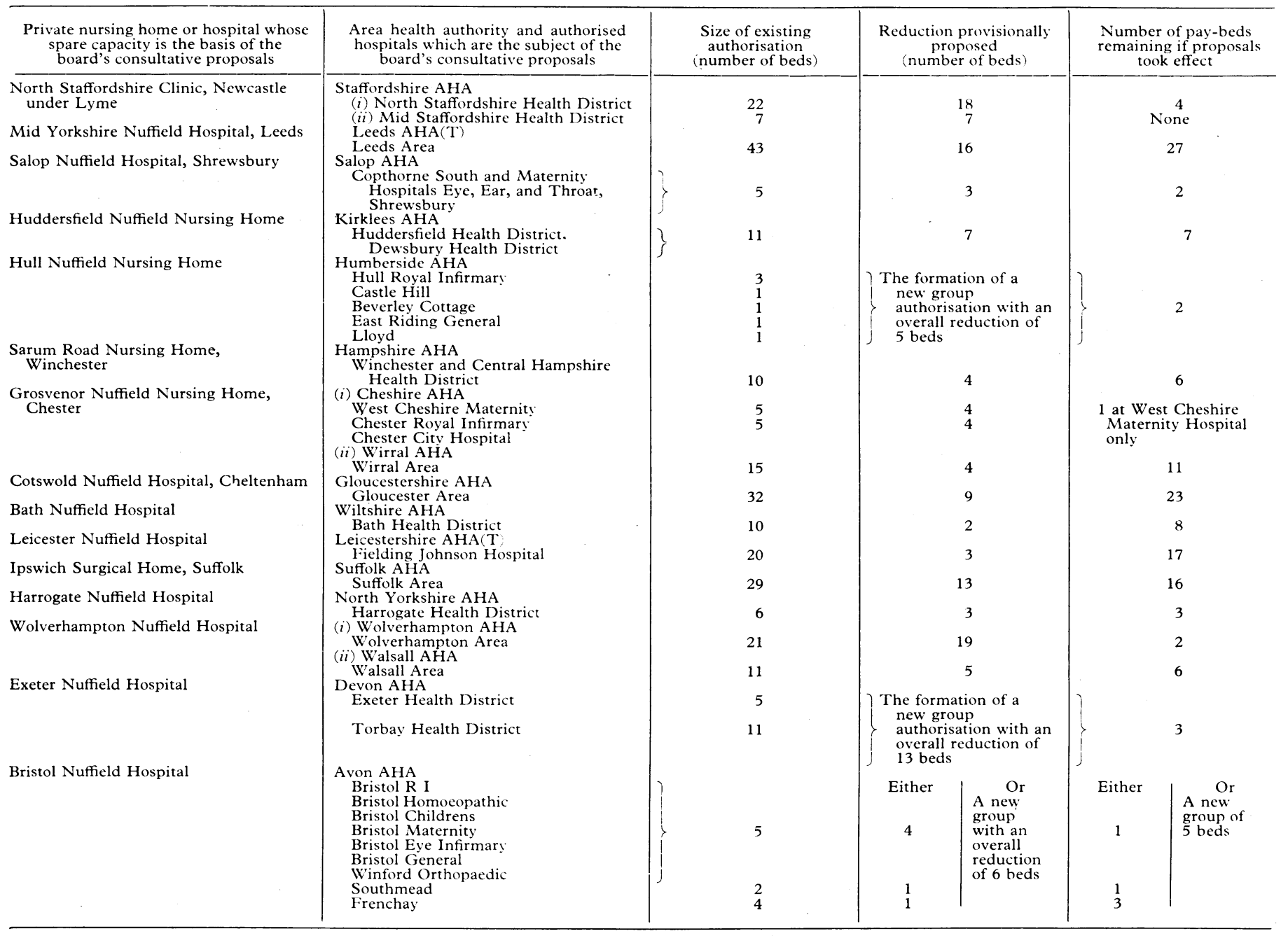

Private outpatient consultations cont.

which to hold private outpatient consultations, irrespective of whether the present facilities are afforded to them through Section 66, a rental agreement, or both.

In its 1977 annual report ( 1 April, p 870) the board acknowledged that "the pace at which we shall be able, in future, to submit proposals for the revocation of authorisations will depend largely on factors outside our control, apart, perhaps, from our use of the 'due warning' provision. The major factors will be strength of demand for private medicine, the rate of expansion of the private sector and the regular supply of basic information on the use made of, and the availability of, private medical facilities." The last the board regards as the most crucial and it is the one in which the board emphasises that it will need continuing help from consultants.

The NHS Act 1977 retained specific provision for the protection of consultants who do not wish to work whole time. But the revocation of authorisations for the use of pay-beds, diagnostic facilities, or other facilities in NHS hospitals for private patients will reduce opportunities for private practice. So it is important that the board is given full and accurate information. Figures may show an apparent lack of demand and use, where in fact the demand exists but cannot be put into effect because, for instance, other doctors providing the necessary back-up services do not do private work. Some specialties (particularly obstetrics) will be hit harder than others and those consultants with smaller practices or who are newly appointed and wish to do 